Annotated

Bibliography 


\title{
An Annotated Bibliography of Translation Studies Books Published in 2017
}

DEEPA $V$.

\begin{abstract}
Albir, Amparo Hurtado (ed.). 2017. Researching Translation Competence by PACTE Group. Amsterdam: John Benjamins Publishing Company.
\end{abstract}

This book is an outcome of the Translation Competence (TC) research conducted by the research group, Process in the Acquisition of Translation Competence and Evaluation (PACTE) formed in 1997 to investigate the Acquisition of TC, its characteristics, to develop and test instruments to measure $\mathrm{TC}$ and so on. It is argued that TC is qualitatively different from bilingual competence which is empirically tested through comparing foreign language teachers and professional translators using cognitive and textual methods. This work also incorporates the study of the acquisition of TC in trainee translators analysing translators in six language pairs came under study: English-Spanish, German-Spanish, FrenchSpanish, English-Catalan, German-Catalan, French-Catalan.

Borodo, Michal; House, Juliane; and Wojciech, Wachowski (eds.). 2017. Moving Texts, Migrating People and Minority Languages. Singapore: Springer.

This volume brings together different perspectives on the issue of translation, migration, diaspora and minority languages and identity shared in the First International Translingua conference held in Poland in 2015. This book is divided into three parts that discuss minority language and multilingualism, migration and movement. Some of the chapters conceive translation in a broad and metaphorical sense. Translation is 
not only perceived as a linguistic transfer from one language into another but as a form of linguistic and cultural expression, negotiation and transformation resulting from the tensions between conflicting identities.

Camus, C Carmen; Castro, G Cristina; and Julia T. Williams Camus (eds.) 2017. Translation, Ideology and Gender. United Kingdom: Cambridge Scholars publishing.

This edited volume is a fruitful outcome of the first international conference on "Translation, Ideology and Gender" that took place in Santander in November 2015. This book has three sections each focusing on a specific topic. This work sheds light on a less explored area within Gender and Translation Studies such as gender issues in translating scientific discourse especially health discourse, women writing, censorship, reception under the repressive Spanish regime, gender policies and identity issues in magazines and so on.

Ciocca, Rossella and Srivastava, Neelam. (eds.) 2017. Indian Literature and the World: Multilingualism, Translation and the Public Sphere. United Kingdom: Palgrave Macmillan Publication.

In this edited volume, Rossella and Neelam offers a fresh take on contemporary Indian writing. They ascertain the need to approach Indian literature, which is multilingual, translational, comparative, located and internationalist, from a different perspective. It departs from the traditional central periphery model as well as the post-colonial theoretical approaches which have always tended to focus mostly on Indian English writings ignoring the myriad cultural and linguistic varieties that contemporary Indian writing encompasses. The concept of 


\section{Deepa V.}

the public sphere is used as their analytical framework to analyse the specificities of the Indian literary and cultural spheres.

Chesterman, Andrew. 2017. Reflections on Translation Theory: Selected Papers from 1993-2014. Amsterdam: John Benjamins Publishing Company.

This book offers a collection of 28 papers that attempt a conceptual analysis of various basic concepts and ideas in translation theory and methodology. These papers are grouped under nine thematic sections. Each section focuses on basic and general issues within Translation Studies such as norms, hypotheses, similarities and differences, "universals", descriptive and prescriptive factors. Various concepts like causality and explanations, translation ethics, and the sociological turn are elucidated with examples.

Desjardins, Renee. 2017. Translation and Social media: In Theory, in Training and in Professional Practice. United Kingdom: Palgrave Macmillan Publication.

Renee explores in detail the connection and interaction between online social media (OSM) and translation. He discusses the challenges, its scope and relevance, its impact on translation theory, training and practice. He analyses the way OSM affects human communicational behaviour and also translation from how translators translate to the content and language of translation on these social platforms. OSM is also becoming a platform for significant activist and social movements gain which makes it a crucial source for social media studies. It is argued that the digital age demands a new approach to translation training programmes with an 
integration of OSM literacy and competency which can provide new visibility to translators.

Hatab, Wafa Abu. 2017. Translation across Time and Space. United Kingdom: Cambridge Scholars Publishing.

This work contains papers by renowned scholars from across the globe addressing issues of translation in a variety of languages like Arabic, Greek, French etc., and cultures. These studies explore various aspects of translation such as translator's visibility and invisibility in literary translation, pragmatic issues in literary translation while translating culture specific concepts such as politeness, gender, body part idiom, challenges involved in translating political texts, the professionalization process of interpreting and the issue of diglossia and interpreting in courtrooms.

Jimenez-Crespo, Miguel A. 2017. Crowdsourcing and Online Collaborative Translations: Expanding the Limits of Translation Studies. Amsterdam: John Benjamins Publishing Company.

This work gives an overview of crowdsourcing and collaborative translation- its origin, definitions, typologies and existing research trends- and critically engages with its revolutionary implications for translation theory and practice and also with its influence on other areas of Translation Studies such as translation training, cognitive translatology, corpus based Translation Studies, and so on. It also takes into consideration the challenges posed by these novel platforms and practices for translation. Looking at these phenomena from various perspectives such as text linguistic approach, sociological approach etc., the author ascertains the significance of these developments to Translation Studies. 
Deepa V.

Laviosa, Sara; Pagano, Adriana; Hannu Kemppanen, and Meng Ji. 2017. Textual and Contextual Analysis in Empirical Translation Studies. Singapore: Springer.

This work discusses the significance of integrating various research methods; corpus-based, corpus-assisted, corpusoriented or corpus- driven methods in empirical translation studies by demonstrating through the papers how quantitative and qualitative analysis of corpus data can throw light onto the dynamics of translation activities and products in particular social and cultural backgrounds. This book covers latest empirical findings of Translation Studies in Europe, Latin America and the Asia-Pacific. It attempts to bridge the gap between corpus-based textual analysis and analysis of socio cultural contexts in corpus translation research and proposes that the gap can be closed by exploring novel quantitative methods adapted from related fields of enquiry.

Rehana Mubarak-Aberer. 2017. Translating Politeness Across Englishes: The Princess and the Pea. New York: Peter Lang.

The author analyses the way politeness is translated into English. Politeness being an abstract and culture specific concept, author argues that translation is the prerequisite for politeness research and polite communication. Since it is culture specific, it is hypothesized that human beings with similar lingua-cultural biographies are more likely to share patterns of perceiving and realizing politeness in English than are individuals with diverging lingua- cultural biographies. This hypothesis is tested through an empirical analysis of politeness in written communication using a multiple choice survey in fictitious customer-support communication contexts 
and through analysing messages sent to and from customer support accounts on the social networking platform Twitter.

\section{Reznikova, Zhanna. 2017. Studying Animal Languages Without Translation: An Insight from Ants. Switzerland: Springer.}

In this book, the author discusses the various methods developed to study animal communication and its results and highlights a conceptually distinct approach that is based on ideas of information theory which attempts to study a language and evaluates its capabilities through measuring the rate of information transmission. The experimental paradigm, the methodology, its scope and significance are illustrated through the experiments on ants. While most studies on animal communication try to decipher animal language through intermediary artificial languages thus translating their linguistic skills into adopted human languages, this work attempts to study about their natural communication system.

\section{Schwieter, John W.; and Ferreira, Aline (eds.). 2017. The Handbook of Translation and Cognition. New Jersey: Wiley Blackwell.}

The Handbook of Translation and Cognition provides a comprehensive and critical overview of translation and interpretation studies and its interaction with cognitive studies. It discusses the existing theories, ongoing research in translation and cognition, various methodologies adopted for these researches and so on by bringing together contributions from international experts affiliated with institutions and research centres in 18 countries. This handbook has six sections, each section focussing on specific aspects like theory, methodology, characteristics of translators and workplace and 
Deepa V.

issues of competence, training and interpreting. The concluding chapter also discusses the future of Cognitive Translation Studies- its scope, relevance and further possible research in these areas.

Summers, Caroline. 2017. Examining Text and Authorship in Translation. United Kingdom: Palgrave Macmillan Publication.

In this work, Caroline Summers explores the role played by various institutional agents in the reconstruction of authorship in the target culture through translation which is distinct from the 'original' authorship in the source culture. From the selection of texts to translation, circulation and its approval by the target readership, all these contribute to a new understanding and imagining of a writer's identity. Taking Christa Wolf, a noted German writer as a case study, Summers looks at how unequal exchange of translation poses challenge to the authority of source language or source account of the author when it is received by a more powerful target language. Summers combines Foucault's notion of authorship with a sociological theory of narrative and looks at authorship as a social narrative constructed through various discursive frameworks.

Sutter, Gert De; Lefer, Marie Aude; and Delaere, Isabelle (eds.). 2017. Empirical Translation Studies: New Methodological and Theoretical Traditions. Germany: De Gruyter Mouton

This volume explores the concept of translational behaviour within the framework of empirical translation studies. It aims to bring together advanced quantitative research based on large corpora that can provide evidence for the effect of factors on 
translational behaviour and to analyse how other methods from related fields can improve the descriptive and explanatory accuracy of corpus based results. Each chapter in this volume addresses issues that can affect translational behaviours like the issue semasiological salience, language mediation, machine intervention, interplay between text register and translation method and the differences in SL and TL typology.

To be continued in the next issue... 